\title{
EL DIEZMO COMO UNA EXPRESIÓN DE FE
}

[Tithing as a expression of faith]

\author{
Paul B. Petersen \\ ppetersen@andrews.edu \\ Danish Union of Churchers Conference \\ Naerum, Dinamarca
}

Recibido: $10 / 11 / 2018$

Aceptado: 15/01/2019

\section{Resumen}

El diezmo desempeñó un papel importante en la economía de las sociedades desde el antiguo Israel hasta los días de la Europa moderna. Si bien es cierto que es importante reafirmar la naturaleza del diezmo como señal de lealtad hacia Dios por parte de su iglesia; no obstante, la mayoría de estudiosos, especialmente pentecostales y carismáticos, prefieren enfocarse en los beneficiones materiales que uno puede obtener de Dios al diezmar. Por lo tanto, el propósito de este artículo es ir tras una motivación teológica para diezmar, bíblicamente fundamentada, con énfasis en la relación que hay entre el diezmante y Dios. Para ello, se recurrirá a las dos narrativas del Génesis, en donde se menciona al diezmo por primera vez en la Biblia. Para concluir, los hallazgos serán vistos desde una perspectiva cristológica.

Palabras clave: Dios, Israel, diezmo, cristología, iglesia

\begin{abstract}
Tithing played a significant role in the economy of societies from early Israel to the days of modern Europe. While it is important to reaffirm the nature of tithing as a sign of loyalty to God, most scholars, especially Pentecostals and charismatics, prefer to focus on the material benefits one can obtain from God by tithing. Therefore, the purpose of this article is to pursue a biblically grounded theological motivation for tithing with emphasis on the relationship between the tithe and God. So, to find the theological motivation given in the Bible for tithing, I will turn to the two narratives in Genesis, in which tithe is mentioned in the Bible for the first time. Finally, the findings will be viewed from a Christological perspective.
\end{abstract}

Keywords: God, Israel, tithing, cristology, churc 


\section{INTRODUCCIÓN}

El diezmo desempeñó un papel importante en la economía de las sociedades desde el antiguo Israel hasta los días de la moderna Europa. Tradicionalmente, los defensores del uso del diezmo, al sostener y justificar el principio, han subrayado el tema de la ley. Diezmar es una obligación, un deber ante una entidad jurídica. Este enfoque ha sido tomado como natural, en parte, a causa de su enorme importancia práctica para la sociedad como para las iglesias. ${ }^{1}$

No obstante, en realidad poco se ha escrito acerca del tema y donde esto se ha hecho, el desarrollo del carácter y los beneficios en forma de bendiciones materiales, a veces, ha sido enfatizado más que una fiel relación con Dios. ${ }^{2}$ Reafirmar la naturaleza obligatoria del diezmo como señal de lealtad hacia Dios y su iglesia es importante; sin embargo, el propósito de este artículo es ir tras una motivación teológica para diezmar, bíblicamente fundamentada, con énfasis en la relación que hay entre el diezmante y Dios. ${ }^{3}$

No es sencillo desarrollar un fundamento teológico sistemático en base a los textos bíblicos. En general, las Escrituras no analizan ni sistematizan sus temas en ningún sentido moderno u occidental. El asunto del diezmo no es la excepción. La inmensa mayoría de textos concernientes al diezmo se encuentra en la sección legal del Pentateuco. No obstante, como es común en las leyes mosaicas, solo pocas referencias proveen alguna razón teológica explícita para su existencia. Como han observado algunos diccionarios teológicos conservadores, las leyes, cuando son

${ }^{1}$ La Iglesia Adventista del Séptimo Día pertenece a aquellas denominaciones que comprenden que el diezmo es un principio bíblico aplicable también a la era cristiana. Sin embargo, en diversos países católicos y protestantes de Europa, el diezmo fue mantenido como una ordenanza social hasta dentro del siglo XX.

${ }^{2}$ Ver, por ejemplo, el estudio del diezmo en Asociación Ministerial de la Asociación General de los Adventistas del Séptimo Día, Creencias de los Adventistas del Séptimo Día (Buenos Aires: Asociación Casa Editora Sudamericana, 1988), 271-277.

3Desde una perspectiva adventista del séptimo día, Ángel Manuel Rodríguez ha producido varios artículos sobre el diezmo a los cuales quiero dar crédito, Ángel Manuel Rodríguez, Stewardship Roots: Toward a Theology of Stewardship, Tithe and Offerings (Estados Unidos, Silver Spring: Adventist Stewardship Ministries, 1994) y Tithing, the New Testament and the Christian Church (Estados Unidos, Silver Spring: Biblical Research Institute, 2001). El presente artículo se ha desarrollado sobre el cimiento puesto por el Dr. Rodríguez, pero llega más allá en un intento de poner énfasis particular en el aspecto de la relación personal con Dios al diezmar. 
vistas en su totalidad, revelan claramente: el qué, el a quién, y el dónde del diezmo. ${ }^{4}$ Sin embargo, estas mismas leyes dicen poco acerca del por qué.

Es cierto que es posible deducir de estas leyes, que el diezmo en el Antiguo Testamento es una señal de aceptación del servicio del templo y del sacerdocio como instaurados por Dios. El diezmo siempre es entregado a un representante para una institución social o religiosa mayor. Entregar el diezmo a esta unidad ejemplifica la lealtad. Pero tales deducciones, aunque obviamente verdaderas, son solo deducciones secundarias. El origen divino y la necesidad de estas instituciones colectivas son remarcados por este medio, pero la interrogante del por qué Dios escogió el diezmo como tal señal de lealtad, todavía es dejada parcialmente sin respuesta.

Tampoco es de alguna ayuda regresar al origen del diezmo, por la simple razón de que nunca se dice algo acerca de la situación en la que surgió el concepto del diezmo - en contraste, por ejemplo, a la cuestión del sábado. En los dos casos en Génesis donde el diezmo es mencionado en un escenario narrativo, se da por supuesto que ya era una costumbre establecida (Gn 14:19-20 y 28:20-22). ${ }^{5}$ A pesar de esto, en este artículo, se propone que es exactamente en estas narrativas que la motivación teológica para el diezmo debe ser encontrada.

Teniendo en cuenta la estructura literaria del Pentateuco, es juicioso entender las leyes del diezmo, tal como todas las otras leyes, contra el trasfondo de las narrativas en Génesis. Al leer las leyes mosaicas, cualquier israelita las entendería sobre aquella base. La motivación teológica para el sábado, por ejemplo, fue hallada en el relato de la Creación (Gn 2:1-3; cf. Éx 20:11). El concepto

4J. G. S. S. Thompson, “Tithe”, en The New Bible Dictionary, ed. J. D. Douglas (Grand Rapids, MI: Eerdmans, 1962), 1984. Ronald B. Allen, "Tithe", en Theological Wordbook of the Old Testament, ed. R. L. Harris, G. L. Archer Jr. (Chicago: Moody Press, 1980), 2:703. En adelante TWOT. Los comentaristas histórico-críticos que dan por sentado el desarrollo evolutivo de las fuentes de J, E, D y $\mathrm{P}$, entienden las varias referencias al diezmo en el Pentateuco como contradictorias e incoherentes, y el punto de vista conservador común del judaísmo es considerado como una racionalización tardía y posterior. Ver, por ejemplo, H.H. Guthrie, Jr., "Tithe", en Interpreter's Dictionary of the Bible, ed. G. A. Buttrick (Nashville: Abingdon, 1990), 4:654-655 y R. North, "Tithe", en Theological Dictionary of the Old Testament, ed. G. J. Botterweck y H. Ringgren (Grand Rapids, MI: Eerdmans Publishing, 2001), 11:404-409. En adelante TDOT.

${ }^{5}$ Diezmar en una forma u otra parece haber sido bastante común en las culturas del Antiguo Cercano Oriente. Ver North, “Tithe”, TDOT, 11:404-405. 
de sacrificio se originó en el Edén después de la caída, pero recibió un profundo revestimiento teológico desde la historia del sacrificio de Isaac por parte de Abraham en Génesis 22:1-19. De igual modo, ningún israelita educado religiosamente traería el diezmo sin asociarlo a las narrativas de Génesis, en las cuales el diezmo aparece en la Torá por primera vez. La teología de las leyes mosaicas está incrustada en las narrativas de Génesis y la primera parte de Éxodo que preceden al corpus legal. Esta comprensión de las narrativas en Génesis como transmisores teológicos coincide con la argumentación de Pablo en sus epístolas del Nuevo Testamento. El apóstol dedujo parte de su enseñanza sobre la justificación de las narrativas de Abraham (Rom 4) y, del mismo modo, estos eventos del período patriarcal proporcionaron la base para distinguir entre la Jerusalén terrenal y la celestial, y la relación del cristiano con las leyes mosaicas como un todo (Gá 4:21-31).

Por lo tanto, para encontrar la motivación teológica para diezmar brindada por la Biblia, se recurrirá a las dos narrativas del Génesis, en donde se menciona al diezmo por primera vez en la Biblia. Para concluir, los hallazgos serán vistos desde una perspectiva cristológica.

\section{EL DIEZMO EN GÉNESIS: \\ LAS NARRATIVAS TEOLÓGICAS BÁSICAS}

A primera vista, las dos narrativas en cuestión parecen tener poco en común ${ }^{6}$, dado que las situaciones son completamente diferentes. En Génesis 14, Abram ha salido victorioso de una guerra, mientras que en Génesis 28 Jacob es un fugitivo huidizo. El qué no es el mismo: en Génesis 14:17-24, Abram devuelve a Dios una décima parte del botín de guerra; en Génesis 28:20-22, Jacob promete devolver a Dios la décima parte de lo que él podría recibir en el futuro. Los receptores, el a quién del diezmo, no son idénticos: en Génesis 14:20 Abram trae su diezmo a Melquisedec, el sacerdote-rey de Jerusalén; por otro lado, nunca se dice a quién en realidad Jacob entregaría su diezmo. Sin duda, los personajes

6Para una buena introducción a la lectura de las narrativas bíblicas en general y las narrativas de Génesis en particular, ver Laurence A. Turner, Genesis, Readings: A New Biblical Commentary (Sheffield: Sheffield University Press, 2000). 
tampoco son similares: aunque se llamaba Abram, él era el "padre de los fieles"; mientras Jacob es el engañador traicionero. A pesar de estas diferencias, las narrativas comparten varias características que iluminan la búsqueda de la teología del diezmo.

\section{ORACIÓN Y ADORACIÓN}

Ambos ejemplos del diezmo están colocados en un contexto de oración y adoración. La bendición o acción de gracias de Melquisedec tiene la forma de una oración y, con este hecho en mente, no es improbable que cuando Melquisedec sacó pan y vino se estuviera realizando un ritual o comida pactual.7 De manera similar, la promesa de Jacob es indudablemente una oración. ${ }^{8}$ La importancia de esta observación es intensificada por el hecho que, aunque la oración y el diálogo con Dios constituyen un asunto principal en Génesis, solamente unas pocas oraciones registradas están presentes en el libro. ${ }^{9}$

La caída quebró la relación personal entre Dios y el hombre. Génesis relata el trágico desarrollo histórico en el cual Dios, que una vez caminó sobre la tierra con el hombre, tenía que revelarse a través de mediadores. Acercándose a él mediante sacrificios, el hombre empezó a adorar e "invocar el nombre de Jehová" (Gn 4:26). Noé continuó está adoración después del diluvio (Gn 8:20). Cuando Abraham e Isaac viajaron por la tierra prometida, construyeron altares y adoraron (Gn 12:7, 8; 13:4, 18; 26:25). Durante su escape, Jacob erigió ante Dios una maș-șēbāh en Betel (Gn 28:18) antes de su promesa de diezmar. Asentado una

7Como ha sido sugerido por N. Airoldi, "La cosidetta 'decima' israelitica antica", Bíblica 55 (1974): 193-194. Los comentarios conservadores mayormente asumen que el pan y el vino simplemente eran la provisión para los exhaustos soldados. Ver Gordon J. Wenham, Genesis 1-15 de Word Biblical Commentary, ed. David A. Hubbard y Glenn Barker (Waco, TX: Word Books, 1987), 1:316; quien rechaza la noción supuesta por Airoldi y Victor P. Hamilton, The Book of Genesis: Chapters 1-17 (Grand Rapids, MI: Eerdmans Publishing, 1991), 408-410. Sin embargo, se debe entender aquí que, en las culturas de aquel tiempo, a menudo la comida por sí misma transmitía connotaciones religiosas (Gn 31:54).

8El hecho que Jacob en su discurso ante Dios alterna entre la 3ra y la 2da persona, no debe ser motivo de confusión. Este fenómeno es común entre los discursos en oraciones y también se encuentra en discursos interpersonales del Antiguo Testamento, aunque no siempre se hace evidente en las traducciones. Los ejemplos incluyen Salmos 74:12-13; 104:2-3; Cantares 4:2 y Daniel 2:20-23.

${ }^{9} \mathrm{~A}$ saber, la oración realizada por el siervo de Abraham en Génesis 24:12-14 durante su expedición para hallar una esposa adecuada para Isaac, y la petición de Jacob para ser librado de Esaú en Génesis 32:9-12. 
vez más en la tierra de su padre, Jacob continuó la costumbre de temor y respeto de sus padres (Gn 33:20), y regresó a Betel a la orden de Dios para edificar un altar en el lugar donde muchos años atrás, Dios mismo se le había revelado y le había hecho conocer sus promesas (Gn 35:1, 3, 7).

Es contra el trasfondo de este tema dominante de adoración dentro de Génesis que las dos referencias al diezmo deben ser entendidas. Diezmar es un acto de adoración. Como la oración, es una respuesta al Dios que ha hablado, que se ha revelado al hombre y que ha intervenido en su vida. Al diezmar, Abraham y Jacob reconocieron un poder más alto que ellos mismos, "Jehová, Dios Altísimo", " creador, el Dios Altísimo" (Gn 14:22; 18-20).

De esta manera, el concepto del diezmo es complementado por la adoración. Pero el movimiento es recíproco. La teología de la adoración es enriquecida por el concepto del diezmo. La adoración no está vinculada simplemente a la realización apropiada de los rituales. La adoración no solo se ocupa de la actitud mental del hombre al meditar sobre lo divino. En la adoración a Dios, el hombre no solo comparte tiempo santo con el Creador, sino que al traer sus diezmos y ofrendas comparte con el Dador los frutos de las actividades y esfuerzos humanos. ${ }^{10} \mathrm{La}$ adoración abarca la totalidad del hombre.11 Así, el diezmo y la acción de diezmar llegan a ser santos - “es cosa dedicada a Jehová” (Lv 27:30).

\section{LA BENDICIÓN}

Ambas narrativas están también dentro de un contexto de bendición. Para captar la significancia de este hecho para la comprensión del diezmo, se discutirá el rol de la bendición dentro del flujo de las narrativas en Génesis, contra el

${ }^{10}$ Nota del traductor: Aunque Petersen esta lo cierto al afirmar que el adorador comparte el tiempo y los recursos con Dios, se debe aclarar que el propietario de las cosas es Dios y el adorador solo puede devolver o compartir aquello que no le pertenece, pues como David dijo: "De lo recibido de tu mano te damos" (1 Cro 29:14). Este concepto también aclarado por Petersen en párrafos posteriores, en el contenido que precede a la nota 24 y lo desarrolla ampliamente bajo el subtitulo "Dios creador y sustentador".

${ }^{11}$ En su preludio a una teología del diezmo, Rodríguez incluye una descripción de hombre como "un ser físico", "un ser espiritual", "un ser intelectual", y "un ser social", Rodríguez, Stewardship Roots, 5-8. 
trasfondo del concepto teológico de la bendición en el Antiguo Testamento en general.

Como parte de un saludo,12 una bendición es una expresión de desear lo mejor para alguien. Esta consiste; sin embargo, no solo en palabras, sino en acciones. Cuando bendice, el dador comparte el poder de salud y bienestar con el receptor. ${ }^{13}$ Bendición es en un sentido una compartición de dones. Cuando Dios es el que comparte, Él otorga sus dones al hombre.

En muchas religiones, desde el Antiguo Cercano Oriente hasta el día de hoy, la bendición ha sido concebida como mágica, siendo efectiva cuando se efectúan los rituales apropiados y se pronuncia la fórmula verbal correctamente. Este no es el caso en el Antiguo Testamento porque la bendición es entendida como parte de una relación interpersonal. Esto se destaca en el hecho de que, no solo Dios como Ser Superior comparte sus dones con las criaturas inferiores, sino que el movimiento es recíproco. El hombre también aparece bendiciendo a Dios (ver, por ejemplo, Gn 24:27; 1 S 25:32, 39; 1 R 1:48; Sal 18:47; 28:6; 31:32; 41:14). ${ }^{14}$ Debido a que el hombre no puede traer a Dios nada que Él no haya provisto, bendecir a Dios llega a ser una expresión de gratitud y acción de gracias (como en Sal 66:20; 113:2; Dn 2:20). Al bendecir, el hombre alaba a Dios, ofreciendo el "fruto de labios que confiesan su nombre" (Heb 13:15). ${ }^{15}$

12El "saludo" (Gn 47:7; 1 Sam 13:10; 25:14) incluye la "despedida alentadora" (Gn 24:60; 28:1) y la "felicitación" (Éx 39:43; 2 S 8:10) y es parte del sentido de la raíz también en términos cognados, ver C. A. Keller y G. Wehmeier, "\$rb”, en Theological Lexicon of the Old Testament, ed. E. Jenni y C. Westermann (Peabody, Mass.: Hendrickson Publisher, 1997), 1:266, 271. En adelante TLOT.

${ }^{13}$ Keller y Wehmeier, TLOT, “\$rb”, 1:68. Se refieren al significado de bendición como "poder benevolente" o "poder generador de salud" (268). John N. Oswalt lo define como "dotar con poder para el éxito, prosperidad, fecundidad, longevidad, etc"., John N. Oswalt, “\%rB”, TWOT, 1:132.

14Josef Scharbert, "\$rb", TDOT, 2:284; vincula esto a las relaciones personales íntimas. Christopher Wright Mitchell está fundamentándose en la tesis básica de Scharbert y está yendo más allá en un intento de "definir las connotaciones relacionales de la bendición" más plenamente, The Meaning of brk "to Bless" in the Old Testament, SBL Dissertation Series 95 (Atlanta, GA: Scholars Press, 1987), 26-27. En ocasiones, las traducciones se sienten incómodas con la idea del hombre bendiciendo a Dios y evitan el término "bendecir". Por ejemplo, Salmos 16:7; 96:2; 103:1; 104:1.

15Para una discusión más extensa del concepto teológico de la bendición en el Antiguo Testamento, ver también Paul Petersen, "The Theology and Function of the Prayers of the Book of Daniel" (Tesis doctoral, Andrews University, 1999). 
El concepto de bendición desempeña un papel único en Génesis, ${ }^{16}$ y su aparición primaria es hallada en los bloques narrativos de los patriarcas Abram y Jacob. El llamamiento de Abram en Génesis 12:1-3 contiene promesas divinas de bendición no solo para él y sus descendientes, sino también para todos a través de él. Por medio de él y por medio de la gente, cuyo padre él llegaría a ser, las maldiciones que azotaban la tierra debido a la caída debían ser contrarrestadas. ${ }^{17}$

La descripción del diezmo en Génesis 14 contiene la siguiente referencia a la bendición. En una escala más pequeña, Abram ya había cumplido parte de la promesa divina de ser una bendición para las naciones a través de su acto de librar a los cautivos de Sodoma y Gomorra de las manos de los reyes del oriente. La doble bendición de Melquisedec (Gn 14:19-20) es una expresión de gratitud hacia Abram y hacia Dios, pero también un reconocimiento del hecho que el Altísimo ha dado esta victoria a Abram. Al dar el diezmo a Melquisedec, Abram coincide con él rindiendo tributo a Dios como la única fuente de su logro. Dios ha bendecido a Abram compartiendo su poder. Melquisedec y Abram responden en acción de gracias y gratitud bendiciendo a Dios a través del diezmo.

A primeras luces, los eventos en Luz (Betel) en Génesis 28 no hacen referencia al concepto de bendición. La raíz hebrea brk no está presente. A pesar de eso, cuando Jacob muchos años más tarde relata los cumplimientos de las promesas de Dios que se le dieron en el sueño nocturno, él las entiende como si hubieran sido bendiciones (Gn 48:3). Además, la dramática historia de la huida y retorno de Jacob es puesta en el contexto de una lucha personal por una bendición mucho más profunda que los bienes materiales, la cual es vista inicialmente por Jacob como el contenido básico de las promesas divinas (es significativo que el voto hecho por Jacob en Gén 28:20 se refiere a las cosas esenciales de la vida y no a los más extensos aspectos de las promesas de los vv. 13-14).18

16Keller y Wehmeier enlistan 88 apariciones de la raíz brk en Génesis, TLOT, "\$rb", 267, comparadas con las 7, 3 y 17 veces que aparece en Éxodo, Levítico y Números respectivamente. En Deuteronomio, el número de apariciones es de 51, lo cual indica el fuerte vínculo temático entre Génesis y Deuteronomio.

${ }^{17}$ Esta conexión entre el llamado a Abram y las cinco maldiciones originales de la humanidad en Génesis 3-11 es notada también por Keller y Wehmeier, TLOT, “\$rb”, 277-278.

${ }^{18}$ Es la posición tradicional ver el voto de Jacob solamente como una expresión de su absoluta gratitud a Dios por las promesas recibidas durante el sueño nocturno, leyendo el 
El trasfondo para la huida de Jacob es su deshonesto robo de la bendición legal de Isaac, descrito en el capítulo anterior. El diálogo entre padre e hijo revela el carácter de Jacob quien, al ser interrogado acerca de su identidad, afirmó ser Esaú; no Jacob, el engañador (Gn 27:24-29). ${ }^{19}$ No puede ser coincidencia que, aun cuando los problemas de Jacob en Mesopotamia estaban a punto de culminar y él reconoce abiertamente a Dios como la fuente de la riqueza material que él había acumulado (Gn 31:5, 42; 33:5, 11), al lector solo se le informa por las palabras de Labán que ésto se debe a las bendiciones de Dios (Gn 30:27, 30). Jacob mismo está en busca de una clase más profunda de bendición. Aquí él alcanza aquella bendición en su misteriosa batalla nocturna con el Señor (Gn 32:24-30). El clímax de esta batalla hace eco del diálogo entre Isaac y Jacob muchos años atrás. Al ser interrogado acerca de su identidad, esta vez Jacob admite que él es Jacob, el engañador. ${ }^{20}$ Así, al darse cuenta de que él no es nada, él recibe un nuevo nombre y llega a ser una nueva creación. Dios lo bendice con el perdón mientras que él reconoce su total dependencia de la misericordia de Dios.

Jacob está ahora listo para regresar a Betel (Gn 35:1) donde Dios se le había revelado por primera vez. ${ }^{21}$ Allí Jacob había hecho su voto de hacer del Señor su único Dios y devolverle el diezmo, si él regresaba a buen recaudo de su largo viaje. Por consiguiente, el patriarca quita todos los dioses de su grupo familiar (Gn 35:24), viaja a Betel y construye un altar allí (Gn 35:6-7). El texto no especifica que Jacob,

condicional "si" como "ciertamente". Mientras que no se debe poner en duda el elemento de gratitud por parte de Jacob cuando este se dio cuenta de que Dios estaba con él, puede sugerirse que la narrativa está más matizada. A lo largo de los años, Jacob creció en entendimiento. Ver la afirmación hecha por Elena G. de White, "Aunque su mente comprendió en seguida una parte de la revelación, sus grandes y misteriosas verdades fueron el estudio de toda su vida, y las fue comprendiendo cada vez mejor". Su relación con Dios cambió dramáticamente, como se mostrará brevemente en los siguientes párrafos. Elena G. de White, Patriarcas y Profetas (Buenos Aires: Asociación Casa Editora Sudamericana, 2008), 165. En adelante PP.

${ }^{19}$ Calificativo que se relaciona con el nombre de Jacob, ver Génesis 25:26.

${ }^{20}$ Elena G. de White dice acerca de esta experiencia, "El error que había inducido a Jacob al pecado de alcanzar la primogenitura por medio de un engaño, ahora le fue claramente manifestado. No había confiado en las promesas de Dios, sino que había tratado de hacer por su propio esfuerzo lo que Dios habría hecho a su tiempo y a su modo". $P P, 176$.

${ }^{21}$ Un artículo muy incisivo sobre los aspectos de la vida viajera de Jacob se encuentra en Gordon Tucker, “Jacob's Terrible Burden", Biblical Review 10 (1994): 20-28. 
en armonía con su voto, también devolvió el diezmo, pero el lector puede llenar la brecha y complementar aquella información. Sin embargo, la relación de Jacob con Dios se había hecho más profunda. Todo rasgo de ambición había desaparecido. Cuando él cumple su promesa original y devuelve el diezmo, este ya no es entregado como un producto de sus propios logros o como parte de un trato, sino como una respuesta a las inmerecidas bendiciones de la misericordia divina. En otras palabras, Jacob ya no está negociando con Dios.

Inmediatamente después, Dios se revela una vez más a Jacob con una bendición y una repetición de las promesas (Gn 35:9-13). Durante el resto de su vida, Jacob vive en la sombra de la bendición divina. Esto puede verse cuando, como un hombre viejo y humilde, Jacob saluda a Faraón en Egipto (Gn 47:7-10) refiriéndose a su experiencia pasada (Gn 48:3), y compartiendo su despedida inspirada con sus descendientes (Gn 48:9, 15-20; 49:25-26, 28).

En el Antiguo Testamento, la bendición es parte de una relación personal mutua entre Dios y el hombre.22 "Aquellos que están erróneamente relacionados con Dios no pueden bendecir (Mal 2:2) ni ser bendecidos (Dt 28) y ninguna palabra eficaz puede alterar esto". ${ }^{23} \mathrm{El}$ diezmo está estrechamente vinculado a la bendición (Mal 3:10) y, por lo tanto, no es simplemente parte de un trato. Al traer el diezmo, los humanos deben reconocer que todos nuestros logros son solo bendiciones de Dios. Respondiendo a estas bendiciones, se bendice a Dios, es decir, se devuelve en gratitud a Dios una pequeña parte de lo que Él ya ha provisto. ${ }^{24} \mathrm{El}$ diezmo es traído a Dios como una alabanza por su bendición de misericordia y perdón divinos. ${ }^{25}$

\footnotetext{
22Oswalt expresa parte de esta verdad, "Ciertamente, el nombre de Dios, la manifestación de su naturaleza personal, redentora, observadora del pacto, está en el corazón de toda bendición". Ver Oswalt, "פּר”, TWOT, 132.

${ }^{23}$ Ibíd.

${ }^{24}$ Es significativo que Elena G. de White titulara uno de sus artículos acerca del diezmo "A Test of Gratitude and Loyalty", [Una prueba de Gratitud y Lealtad] Review \& Herald, 4 de febrero, 1902.

${ }^{25}$ Con referencia a Malaquías 3:10, Creencias de los Adventistas del Séptimo Día, 271. Afirma que "cuando Dios pide nuestros diezmos, no apela a nuestra gratitud ni a nuestra generosidad. $\mathrm{Si}$ bien es cierto que la gratitud debiera tener una parte en todas nuestras expresiones a Dios, diezmamos porque Dios lo ha mandado". En vista de las reflexiones en este artículo, esta afirmación general y categórica debiera ser modificada. Incluso en el contexto de Malaquías, el
} 


\section{DIOS: CREADOR Y PROVEEDOR}

Aunque las dos narrativas ven las bendiciones de Dios desde dos diferentes ángulos, es un pensamiento común ver en ambas que Dios es el Proveedor. Para Jacob en Génesis 28, las provisiones de Dios consisten en las promesas y son todavía futuras. Para Abram, Dios ya había ganado la victoria sobre los enemigos. Sus provisiones son realidades presentes y pasadas.

Abram coincide con Melquisedec al llamar a Dios "Altísimo, creador de los cielos y de la tierra" (Gn 14:22, 19). Mientras que la frase "cielos y tierra" dentro del contexto de Génesis inmediatamente porta asociaciones con el informe de la creación (Gn 1:1), la palabra traducida como “creador" o "dueño" no proviene de la raíz hebrea $b r^{\prime}$ (crear) ni 'sh (hacer, crear), sino de $q n h$, usualmente traducido como "comprar" o "adquirir". Existe un debate sobre si en algunos lugares este verbo puede contener el significado de "crear" o "dar a luz". ${ }^{26}$ Sin embargo, a la vez estas frases paralelas como "Jehová, que hizo los cielos y la tierra" en Salmos 115:15; 121:2; 124:8; 134:3; 146:6; usan el participio del verbo 'āśāh (de 'sh), y obviamente también traen a la mente que la alternativa de qānāh, "adquirir", enfatiza el aspecto de posesión y pertenencia. La expresión "cielos y tierra" es un término inclusivo, 27 el cual indica que todas las cosas pertenecen a Dios.

Esto es apropiado en el contexto de diezmar. Al traer el diezmo, el hombre no le da a Dios lo que le pertenece, sino que le está devolviendo a Él lo que es en realidad de Dios. ${ }^{28}$ Lo que el hombre "posee" o adquiere por sus logros, ya pertenece a Dios. Devolver el diezmo es, por lo tanto, una señal de aceptación de

llamado a diezmar es dado por Dios, quien inicia la conversación con su pueblo y sacerdocio infiel diciendo: "Yo os he amado" (Mal 1:2).

26Para una discusión sobre el tema, ver W. H. Schmidt, "hnq", TLOT, 3:1147-1153. Leonard J. Coppes enlista Salmos 139:13; 78:54; Deuteronomio 32:6; Proverbios 8:22 y Génesis 14:19, 22 como los seis lugares en el Antiguo Testamento donde "qānāh" parece significar "crear"; Leonard J. Coppes, “hnq", TWOT, 2:804.

27Se trata de un así llamado merismo, como los que se encuentran en Génesis 1:1; Isaías 1:2 y Lucas 2:14.

${ }^{28}$ "El diezmo pertenece al Señor, y él nos ordena que le devolvamos lo que le pertenece". Ver, White, La Educación (Buenos Aires: Asociación Casa Editora Sudamericana, 2009), 124. En adelante $E D$. 
su rol como mayordomo de Dios en relación a todos los aspectos de la existencia humana. ${ }^{29}$

\section{EL HOMBRE: UN MAYORDOMO VOLUNTARIO}

Las dos narrativas señalan a Dios como el Creador y Proveedor de todas las bendiciones. El acto de diezmar y el diezmo resaltan una importante característica de cualquier genuina relación personal con Dios. El acto de devolverlo es deliberado y voluntario. Es hecho por elección.

Este aspecto es remarcado en el diálogo entre Abram y el rey de Sodoma. Brusco y mezquino, el rey pagano parece reaccionar fuertemente contra el diezmo de Abram, lo cual implicaba desde luego que el rey estaba perdiendo parte de sus bienes, y él incluso demanda de Abram más de lo que era su derecho de acuerdo a la costumbre. ${ }^{30}$ Abram, en cambio, escoge ser generoso y se abstiene de alguna ganancia personal. De esto se hace evidente que Abram, al compartir el botín, actúa en completa libertad. Así, también su diezmo tiene que ser visto como voluntario.

Esto es incluso más evidente en la narrativa concerniente a Jacob, cuyo acto de diezmar está relacionado a un voto personal y muy deliberado. Al devolver el diezmo en respuesta a los actos de misericordia de Dios, el elemento de elección es esencial para mantener una relación personal con Dios. ${ }^{31}$

\section{RESUMEN}

${ }^{29}$ Devolviendo el diezmo, se está "declarando que Dios es el dueño de toda nuestra propiedad, y que él nos ha hecho mayordomos a fin de que la usemos para su gloria". White, "A Test of Gratitude and Loyalty", Review \& Herald, 4 de febrero, 1902.

${ }^{30}$ Correctamente observado por Wenham, Génesis 1-15, 1:318.

31Elena G. de White acentúa este elemento al afirmar que "cada persona debe llevar con liberalidad los diezmos y las ofrendas a la tesorería del Señor, con buena voluntad y con gozo, porque al hacerlo así recibe una bendición. Es peligroso retener como propia la parte que le pertenece a Dios"; White, Consejos sobre Mayordomía Cristiana (California: Publicaciones Interamericanas, 1971), 71. Este elemento puede ser visto también como una parte integrada de la filosofía subyacente que ella tiene cuando aborda el sistema de diezmo, que considera instituido por Dios como "una educación adaptada para acabar con todo egoísmo, y cultivar la grandeza y la nobleza de carácter"; ver White, Educación, 41. Esto parece particularmente apropiado en el caso de Jacob, y puede preguntarse en general cómo es posible lograr un desarrollo tal del carácter si el diezmo no es pagado voluntariamente. 
Este artículo intentó proveer una base teológica para el diezmo, con énfasis específico en la fiel relación individual con Dios. Para establecer esta base, las dos narrativas en Génesis en las cuales el diezmo es mencionado por primera vez en la Torá (Gén 14:17-24 y 28:11-22), son comparadas dentro del contexto narrativo más amplio de Génesis. El fundamento para esta metodología parcialmente literaria se encuentra en las observaciones de que las leyes mosaicas concernientes al diezmo son oídas y leídas contra este trasfondo, y que las narrativas en Génesis también en relación a otros temas, tales como el sábado y la justificación por la fe, funcionan en el Nuevo Testamento como transmisores de teología.

Viendo los diezmos de Abram y Jacob sinópticamente, cuatro elementos principales vinculan estas situaciones y proveen un fundamento para una comprensión teológica de la institución del diezmo en el Antiguo Testamento y en la Biblia en su totalidad. Primero, el diezmo es puesto en un contexto de oración y es entendido como un acto de adoración. Segundo, el diezmo es descrito en el contexto de bendición: devolviendo el diezmo, el hombre responde a las dádivas divinas, y como parte de una relación mutua con Dios, el hombre agradecido trae su diezmo como una alabanza (o bendición) por la bendición del perdón y misericordia divinas. Tercero, el diezmo es dado a causa de la naturaleza de Dios: Él es el Creador y el Proveedor, y el diezmo denota su total señorío, siendo además una señal de la aceptación que el hombre hace de su rol de mayordomo de todas las dádivas y logros de la vida. Cuarto, como parte de una relación personal entre el individuo y Dios, en la que el hombre debe crecer y desarrollar el carácter, el diezmo debe ser deliberado y voluntario.

\section{CONCLUSIÓN}

Los estatutos acerca del diezmo se encuentran en la sección legal de la Biblia como parte de las leyes mosaicas. No obstante, como se muestra en este artículo, el diezmo no solo es un deber, sino también un asunto de confianza personal en Dios. Este se originó antes de que se diera a conocer la Ley, y Abram, padre de los 
fieles (Gá 3), en gratitud a Dios entregó su diezmo a un sacerdote que no era levita (Heb 7).

Asimismo, desde una perspectiva neotestamentaria, el diezmo puede ser una expresión de fe. La fe genuina en Jesús implica humildad y total entrega a Él como el único Salvador y Señor. Como un acto de oración y adoración, el diezmo ejemplifica el reconocimiento que el cristiano hace de Jesucristo como su Señor (1 Cor 12:3). Por causa del sacrificio de Cristo, el creyente vive en una atmósfera de continua gratitud por las bendiciones recibidas de Dios, "dando siempre gracias por todo al Dios y Padre, en el nombre del Señor Jesucristo" (Ef 5:20; Fil 4:6), y el diezmo puede ser visto como un "sacrificio de alabanza" a Dios, traído por aquellos "que confiesan su nombre" (Heb 13:15). Como creyentes, pertenecemos a Dios. Somos “comprados por precio" (1 Cor 6:20; 7:23), el cual es "nuestra pascua, que es Cristo" (1 Cor 5:7). En la visión de Apocalipsis, Dios y el Cordero son alabados al unísono como Creador y Salvador (Ap 4:11; 5:9-10); somos sus criaturas perdidas, compradas por la sangre del Cordero. Como su posesión, somos mayordomos de todos los dones y logros de la vida (1 Cor 4:2; 1 Cor 4:10). Vivir la fe de Jesús implica la donación voluntaria de un corazón alegre (2 Cor 9:7). La cruz de Cristo revela a un Dios que prefiere la palabra en vez de la espada, la persuasión en vez de la coerción, la libertad en vez de la fuerza, las relaciones de confianza en vez de la sumisión mecánica, y el amor en vez del poder. La gratitud de recibir todas las bendiciones de tal Dios provee la mayor motivación bíblica para el diezmo. 